\title{
Análise econômico-financeira de sistemas de alimentação para equinos
}

\author{
Cabral, G.C.'; Aguiar, L.G.A. ${ }^{2}$ e Peres, A.A.C. ${ }^{\circledR}$
}

Programa de Pós-Graduação em Zootecnia. Universidade Federal Rural do Rio de Janeiro. UFRRJ. Brasil.

2Programa de Pós-Graduação em Tecnologia Ambiental. Universidade Federal Fluminense. UFF. Brasil.

\section{PalaVRAS ChAVE ADICIONAIS}

Análise econômica.

Análise de sensibilidade.

Indicadores econômicos de rentabilidade.

Equinocultura.

Sistemas de alimentação.

\section{RESUMO}

Objetivou-se avaliar a viabilidade econômico-financeira de sistemas de alimentação para equinos utilizando capim-elefante e silagem de milho, como suplementação alimentar. Os indicadores zootécnicos e econômicos para a caracterização dos sistemas de alimentação foram obtidos juntos a um haras de criação de cavalos da raça Mangalarga Marchador. Projetou-se um horizonte para exploração da atividade de 12 anos e, a partir do uso de planilhas eletrônicas, foram projetados os fluxos de caixa a fim de verificar a viabilidade econômico-financeira. Utilizaram-se os indicadores econômicos de rentabilidade: valor presente líquido e taxa interna de retorno, bem como foram realizadas as análises de sensibilidade e risco em cada sistema de alimentação. Os sistemas foram viáveis financeiramente, por apresentarem um valor presente líquido positivo a uma taxa de desconto de $10 \%$ ao ano. A taxa interna de retorno foi de $11,11 \%$ para o sistema de alimentação que adotou o fornecimento de capimelefante, ao passo que para o sistema de alimentação que utilizou silagem de milho, a rentabilidade obtida foi de $11,46 \%$. O preço compra e venda de animais, em especial, de doadoras, foram os itens de maior influência sobre os resultados obtidos para o valor presente líquido. $O$ risco econômico-financeiro para investimento nos sistemas de alimentação foi classificado como baixo.

\section{Economic and financial analysis of equine feeding systems}

\section{SUMMARY}

The objective of this study was to evaluate the economic and financial viability of feeding systems for horses using Elephant-grass and corn silage, as food supplementation. The zootechnical and economic indicators for the characterization of the feeding systems were obtained together with a horse breeding farm of the Mangalarga Marchador breed. A 12-year horizon was projected for exploration of the activity and, based on the use of electronic spreadsheets, the cash flows were elaborated to verify the economic-financial viability. The economic indicators of profitability were used: net present value and internal rate of return, as well as the sensitivity and risk analyzes were performed in each feeding system. The systems were financially viable as they had a positive net present value at a $10 \%$ discount rate per year. The internal rate of return was $11.11 \%$ for the feeding system that adopted the supply of Elephant-grass, while for the feed system that used corn silage, the yield obtained was $11.46 \%$. The purchase and sale prices of animals, especially embryo donor mares, were the items with the greatest influence on the results obtained for the net present value. The economic-financial risk for investment in food systems was classified as low.

\section{Cronología del artículo. \\ Recibido/Received: 17.05.2017 \\ Aceptado/Accepted: 25.06.2019 \\ On-line: 15.07.2019 \\ Correspondencia a los autores/Contact e-mail: \\ afonsoaurelio@id.uff.br}

\section{INTRODUÇÃO}

O Brasil possui o terceiro maior rebanho equino do mundo e o primeiro da América Latina estimado em 5.312.076 cabeças. Deste total, 1.294.079 cabeças encontram-se na região Sudeste, que concentra o maior percentual da população equina brasileira $(24,4 \%)$. Somados aos muares (mulas) e asininos (asnos) estimamse em 8 milhões de cabeças de equídeos no Brasil que compõem o chamado Complexo do Agronegócio do
Cavalo, envolvendo mais de 30 segmentos, distribuídos entre insumos, criação e destinação final. A renda gerada pelo Complexo do Agronegócio do Cavalo no Brasil totalizou R $\$ 16,15$ bilhões (abril de 2015), empregando diretamente 607.329 pessoas. Considerando o fato de que cada ocupação direta proporciona outras quatro ocupações indiretas, estima-se que são gerados 2.429.316 empregos indiretos. Assim, o Complexo é 
responsável, direta e indiretamente, por 3 milhões de pessoas ocupadas (Brasil, 2016).

Segundo CEPEA (2012), o agronegócio é subdividido em quatro segmentos: insumos, agropecuária, indústria (de base agropecuária) e distribuição (transporte, comércio e serviços). O PIB do agronegócio brasileiro, em 2018, representou 21,1\% do PIB total do Brasil. Destes, o setor agropecuário contribuiu com uma parcela 24,1\% (CEPEA, 2019). Em 2016, quando foi feita a atualização do estudo do Complexo do Agronegócio do Cavalo, o PIB total do Brasil foi de 6.259,23 trilhões, o PIB do agronegócio brasileiro foi de 1.429,70 trilhões e o PIB da pecuária foi 426,75 bilhões, em Reais daquele ano. Nesse cenário o PIB do Complexo do Agronegócio do Cavalo, que foi de 16,15 bilhões, representou 0,26\%, 1,13\% e 3,78\% do PIB total do Brasil, do agronegócio e da pecuária, respectivamente (Brasil, 2016; CEPEA 2019).

A Associação Brasileira dos Criadores do Cavalo Mangalarga Marchador - ABCCMM é a maior associação de criadores de equinos de uma mesma raça da América Latina, com aproximadamente 15 mil associados e cerca de 600 mil animais registrados (ABCCMM, 2016). Originária da região Sul de Minas Gerais/BR, a raça Mangalarga Marchador, possui aproximadamente 200 anos de seleção, sendo a mais difundida e comercializada, devido as principais características que apresenta como: comodidade, resistência, rusticidade e docilidade. Frequentemente utilizada em diversas competições como enduro, cavalgada, prova funcional e de maneabilidade, tem o concurso de marcha como sua principal competição (Garcia, 2012). De acordo com a Associação Brasileira dos Criadores do Cavalo Mangalarga Marchador (ABCCMM, 2017) existem aproximadamente 30 mil criadores e proprietários de cavalos da raça Mangalarga Marchador no Brasil.

Particularmente na espécie equina, as diferentes formas de utilização, tais como meio de transporte, trabalho, ferramenta de conquistas e esportes determinaram, desde a domesticação, mudanças na forma de criar e manter os cavalos. As principais mudanças foram a restrição do tamanho das áreas disponíveis ao pastejo, da diversidade de alternativas alimentares e do tempo disponibilizado para o cavalo se alimentar no dia (Dittrich et al., 2010).

Os equinos são classificados como animais monográsticos, pastejadores de vegetais com grande capacidade de seleção do alimento, alimentando-se predominantemente de folhas, colmos e brotos (Salter \& Hudson, 1979; Dittrich et al., 2010). À medida que foram sendo domesticados, os cavalos sofreram restrições no tempo que despende a ingerir alimentos, por restrições físicas ao nível da mobilidade e mesmo ao nível da escolha dos constituintes da própria dieta (Hoskin \& Gee, 2004).

A restrição do tempo de pastejo e/ou a baixa oferta de forragem limitaram a ingestão de forragem pelos animais e, consequentemente, de uma dieta com conteúdos adequados de vários nutrientes, principalmente os carboidratos estruturais, também denominados fibras, que formam a base da dieta dos equinos. Os dois principais fatores limitantes na alimentação dos equinos são: a oferta de forragem e o tempo de pastejo, na maioria das vezes, resultados do modelo utilizado na criação e manutenção dos cavalos para as mais diversas finalidades. A falta de planejamento para o controle destas duas variáveis, aliada à necessidade de alto aporte energético para os cavalos com atividade física intensa, teve com consequência maior preocupação na nutrição de equinos baseada em dietas com conteúdos maiores de energia, ricas em amido.

A necessidade da utilização de volumosos na dieta dos cavalos é indiscutível, mesmo para animais em treinamento, quando há alto requerimento energético e impossibilidade de acesso as áreas de pastagem. Segundo Lewis (2000), o fornecimento de forragens para equinos pode ser por pastejo, feno, forragem verde picada e silagem. O pastejo é a forma que melhor respeita a fisiologia digestiva dos equinos, mas devido à estacionalidade da produção são necessários meios alternativos para a alimentação dos cavalos. Os fenos são os principais alimentos volumosos conservados utilizados nestas situações, mas pesquisas vêm sendo desenvolvidas na busca de alternativas como silagens, pré-secados ou mesmo subprodutos da indústria como, por exemplo, a polpa cítrica e a casca de soja (Quadros et al., 2004; Brandi \& Furtado, 2009). A confecção do feno tem alta dependência das condições climáticas favoráveis e, no preparo da silagem, o clima é um fator secundário, visto que sua conservação ocorre por meio de um processo de fermentação em ambiente fechado. Esta característica proporciona facilidades importantes no indicativo desta forma de conservação de alimentos volumosos, mas também está sujeita a outras implicações como perdas de nutrientes e apodrecimento do material conservado. O consumo de silagem como única forma de alimento foi avaliado por Melo (2008) e verificou-se que o tempo destinado pelos animais ao consumo de três tipos de silagem ad libitum variou entre 8,8 e 10 horas por dia, com maior tempo no período diurno em relação ao noturno. Os animais consumiram somente silagem por 27 dias sem alterações clínicas, hematológicas e dos perfis bioquímicos hepático e renal, demonstrando que este alimento conservado pode ser utilizado na alimentação de cavalos. Em estudo sobre as preferências alimentares dos cavalos entre feno, feno-silagem e silagem, Müller e Udén (2007) concluíram que a silagem foi o tipo de forragem que apresentou maior taxa de consumo e que levou mais tempo a ser consumida. Chegou-se assim à conclusão que o método de conservação da forragem teve impacto na escolha do alimento por parte do animal. Avaliando o valor nutritivo do capim-elefante, do feno de alfafa e do feno de capim-coast-cross para equinos, de acordo com os requerimentos em Energia Digestível (ED) e Proteína Degradada (PD) para mantença propostos pelo NRC (1989), foi verificado por Almeida et al. (1999) que o capim- elefante supriu cerca de $82 \%$ da ED e apenas $22 \%$ da PD, demonstrando ser um alimento bastante deficiente em PD para equinos. Para suprir essa deficiência faz-se necessária a suplementação com alimento concentrado, que normalmente não é produzido na propriedade, mas comprado na forma de ração comercial, ficando o produtor sujeito ao preço de mercado, que tem se mostrado cada vez 
mais desfavorável, principalmente em tempos de crise financeira.

A gestão do negócio agropecuário torna o crescimento do empreendimento rural viável, fortalecendo-o para os momentos de crise, além de prepará-lo para novas oportunidades (Oaigen et al., 2009). Na equinocultura, vários são os setores que permitem ao produtor rural gerar riqueza com a exploração zootécnica, dentre eles: competição, segurança, comercialização de animais e genética, participação em exposições, lazer, etc. Segundo Santos e Lopes (2014), muitas propriedades rurais ainda são gerenciadas de forma empírica, sem conhecimento do custo de produção, que é uma das principais informações de suporte à tomada de decisão. Esse empirismo adotado na equinocultura é reflexo do perfil dos produtores que exploram o setor, pois em sua grande maioria eles desenvolvem a criação de cavalos como sendo uma atividade secundária, não sendo a atividade principal de seu ramo de negócio, que muitas vezes são provenientes de outro setor. Devido a esse comportamento, o produtor empresário precisa, entre outras coisas, considerar a informação como um insumo de grande importância, conhecer o mundo onde está inserido o seu sistema de produção (da porteira para fora) e, também, conhecer bem o seu sistema de produção (da porteira para dentro) (Lopes et al., 2007). Com a apuração dos custos de produção, podem-se adotar estratégias gerenciais na intenção de minimizá-los e aumentar a lucratividade, avaliar o efeito da escala de produção, do tipo de sistema de criação e mão-de-obra, bem como comparar a rentabilidade de sistemas de produção (Buza et al., 2014). Nesse sentido, a utilização de ferramentas de análise econômico-financeira é extremamente importante para a gestão do empreendimento rural.

Objetivou-se analisar a viabilidade econômico-financeira de diferentes sistemas de alimentação para equinos mantidos em pastagem de Brachiaria decumbens, recebendo capim-elefante ou silagem de milho, como fonte de suplementação volumosa.

\section{MATERIAL E MÉTODOS}

O local de realização do estudo foi um haras de criação de equinos da raça Mangalarga Marchador, de propriedade particular, porte médio, pertencente a um criador que visa a produção de animais para a comercialização direta ou por meio de exposições ou leilões. O objetivo do criatório é disponibilizar animais para compradores que buscam animais seleccionados e que apresentam um acompanhamento genético da tropa, através da seleção para as características desejadas de marcha e morfologia. A propriedade rural foi utilizada como referência para a caracterização do sistema de criação de cavalos, bem como as formas de alimentação adotadas no manejo nutricional da tropa.

O haras está localizado na Fazenda Rio do Bálsamo, no município de Rio Claro, estado do Rio de Janeiro, em um lugar conhecido como Serra do Piloto, que dista, em aproximadamente, $50 \mathrm{~km}$ da rodovia Presidente Dutra (BR 116) e $21 \mathrm{~km}$ da rodovia Rio-Santos (BR 101), em uma altitude aproximada de $600 \mathrm{~m}$ do nível do mar. O haras está implantado em uma propriedade de 90 hectares, distribuídos em aproximadamente 64 ha de pastagem, 8 ha de cultura, 15 ha de mata e 3 ha de construção.

A área construída no haras dispõe de 36 baias, 1 galpão de espinhas, 1 galpão de serviço (farmácia, escritório, sala de capim, quarto de ração, selaria, tronco, lavador), 1 redondel, 1 galpão de apresentação, 2 currais de apartação, 1 pista de apresentação, 3 piquetes de garanhão, 7 piquetes maternidade, 1 casa sede, 4 casas de funcionários e uma cozinha com refeitório.

Os animais foram adquiridos de diversos criatórios renomados dentro da raça Mangalarga Marchador, através de compras feitas em visitas as fazendas ou através de leilões chancelados pela ABCCMM. O plantel atual do haras é de 130 animais, divididos entre matrizes, doadoras de embrião, potros(as), garanhões, cavalos castrados e receptoras e a estimativa de produção é de 45 nascimentos por ano, considerando uma perda de $10 \%$ por aborto natural ou morte eventual, pois o objetivo é alcançar um volume de 40 animais comercializados anualmente, sem considerar o descarte e a reposição de receptoras, e considerando a reposição de matrizes e doadoras através de reserva de seleção da produção e aquisição externa. Nessa condição, no presente estudo, o plantel se manteve estável entre 130 e 150 animais, variando ocasionalmente em função do número de receptoras e do período do ano.

Para alcançar melhores índices de produtividade, $\mathrm{o}$ criatório utiliza técnica de transferência de embriões, que viabiliza o processo de melhoramento genético do plantel e a aquisição e venda de animais em sistema de sociedade, muito utilizado hoje pelos criadores da raça. A venda dos animais é feita, praticamente em sua totalidade, dentro do haras. Porém, há intenção do criador em realizar um leilão anual virtual para escoar a produção, passando a ter uma carteira mensal de recebimentos, o que facilita na contabilidade das receitas e dos custos, além de servir como propaganda para o criatório.

A pastagem na propriedade é formada predominantemente de capim-brachiaria (Brachiaria decumbens) associada às pastagens nativas de capim-gordura e grama-batatais. Os piquetes maternidade foram formados por gramínea do gênero Cynodon variedades Estrela-africana e Coast-cross e capim-hemarthria. Os animais são criados em sistema semi-intensivo de produção, onde ficam soltos no pasto e passam parte do dia presos para receber a suplementação e, no caso de algumas categorias, passam a noite nas baias. Todos os animais recebem suplementação no cocho, composta por volumoso e concentrado, calculada de acordo com as exigências nutricionais, segundo NRC (2007).

A suplementação alimentar constitui-se no fornecimento de concentrado de ração comercial seguido de volumoso composto por capim-elefante (Pennisetum purpureum) picado diariamente e fornecido in natura, no cocho. Porém, a capineira de aproximadamente 3 ha, formada há 20 anos, não possui mais suporte suficiente para o trato dos animais, em função do aumento do rebanho e do seu desgaste natural, sendo necessária a sua recuperação e ampliação da área de cultivo. Em função da baixa disponibilidade forrageira ofertada 
na capineira, o proprietário decidiu iniciar o cultivo de milho para produção de silagem, aumentando o tamanho da área cultivada para 8 ha, visando suprir de volumoso a alimentação do rebanho. O sistema de alimentação implantado foi de dois plantios (safra e safrinha), sendo o primeiro plantio realizado em setembro com colheita em janeiro e o segundo plantio realizado em janeiro (ao término da primeira colheita) com colheita em maio. Todo milho plantado foi colhido e ensilado. A partir da abertura do primeiro silo, 40 dias após a colheita, os animais passaram o receber 5 $\mathrm{kg}$ de silagem de milho por refeição, e apenas os animais de baia e os potros desmamados receberam ração concentrada, uma vez que a silagem de milho possui valor nutricional maior que o capim-elefante (tabela I), podendo suprir a exigência nutricional da suplementação alimentar oferecida. Com isso, houve uma redução em 50\% no consumo de concentrado comercial, e buscou-se identificar, através desse estudo, qual dos dois sistemas de alimentação proporcionaria melhores resultados econômico-financeiros ao empreendimento.

A mão de obra utilizada era composta por dois funcionários fixos em cada sistema, para a execução das atividades diárias de manejo dos animais e condução da lavoura, e contratação de dois diaristas para auxílio nas atividades de plantio, colheita e manutenção de cercas e benfeitorias em geral. Cada sistema foi assessorado tecnicamente por um veterinário, responsável pela área de reprodução, e pelo administrador para controle das demais atividades. Todas as atividades relacionadas ao plantio, colheita e ensilagem do milho foram executadas com mão de obra terceirizada.

O trabalho consistiu, portanto, na avaliação da viabilidade econômico-financeira de um criatório de cavalos da raça Mangalarga Marchador, comparando dois sistemas de alimentação volumosa para equinos, com fornecimento diário, no cocho, sendo: um sistema de alimentação baseado no uso de capim-elefante picado e outro sistema de alimentação baseado no uso de silagem de milho. O estudo, o manejo e os dados produtivos utilizados, tiveram como base os indicadores zootécnicos obtidos no haras para ambos os sistemas avaliados, durante dois anos, entre o período de janeiro de 2014 e janeiro de 2016. A partir destes indicadores, projetou-se a exploração da atividade para 10 anos subsequente, caracterizando assim um horizonte temporal no longo prazo, horizonte este que permitiu identificar a recuperação do capital investido na atividade e considerou a vida útil de cercas e pastagem com uma renovação em seis anos.

Cada sistema de alimentação avaliado foi caracterizado através da identificação de todos os insumos utilizados para implantação e exploração da atividade. Foram determinadas todas as saídas e entradas obtidas em cada sistema de alimentação, e tabuladas em planilhas eletrônicas (MS-Excel ${ }^{\circledR}$ ) permitindo uma melhor dinâmica e visualização. Esse levantamento foi realizado por meio da coleta de informações inerentes às práticas ocorridas nos sistemas, tendo como base os resultados obtidos no criatório e os preços de mercado de cada item.

Após o levantamento dos valores de cada item necessário para a atividade, os preços dos mesmos foram deflacionados aplicando-se o IGP-DI (Índice Geral de Preços - "Disponibilidade Interna"), publicado pela Fundação Getúlio Vargas (FGV, 2016), tendo como mês de referência, o mês de março do ano de 2016.

Foi elaborado o fluxo de caixa para cada sistema de alimentação, considerando todos os itens componentes de cada sistema, de acordo com a caracterização realizada e as peculiaridades observadas na propriedade (tabela II), possibilitando a obtenção do fluxo líquido mensal. Na construção do fluxo de caixa, o horizonte de exploração foi ampliado para em torno de 12 anos, a partir da aquisição da área, considerando o tempo de vida útil das cercas utilizadas na propriedade. $\mathrm{O}$ período de prospecção considerado no trabalho foi no longo prazo, pois permitiu identificar o comportamento da atividade, desde que mantidos os indicadores zootécnicos de produção observados na propriedade, o que nos levou a identificar a recuperação de todo investimento realizado, bem como a aplicação do capital financeiro utilizado para o custeio da criação.

As entradas (receitas) do haras foram provenientes principalmente da venda de animais e considerouse o valor financeiro imobilizado na compra da área, na construção de instalações e compra de máquinas e equipamentos. As saídas (despesas) consideradas foram aquelas inerentes ao sistema de alimentação explorado e classificadas em categorias: área, animais, benfeitorias, equipamentos, máquinas, ferramentas, pastagem, plantio da cultura, cercas, alimentação, sanidade, reprodução e mão de obra, entre outros.

Para cada sistema de alimentação foi projetado o fluxo de caixa que caracterizou o sistema de criação de cavalos. Sobre o fluxo de caixa foram aplicadas diferentes taxas de desconto de $8,10,12$, e $15 \%$, definidas a partir de uma taxa mínima de atratividade (TMA). A TMA escolhida para o estudo foi aquela semelhante ao rendimento médio obtido pela caderneta de poupança, no ano de 2015, que foi de 7,88\% a.a. (Portal Brasil, 2016). Em atividades agropecuárias, a caderneta de poupança é um investimendo disponível no mercado financeiro, considerado de baixo risco aos investidores, sendo muito indicada para análise de investimentos em projetos agropecuários. Na avaliação custo-benefício, a análise econômica dos sistemas de alimentação foi realizada adotando-se os principais indicadores econômicos de rentabilidade, o valor presente líquido

\begin{tabular}{lccc}
\hline \multicolumn{4}{l}{ Tabela I. Valores nutricionais do capim-elefante e da silagem de milho (Nutrient values of Elephant-grass and corn silage). } \\
\hline & Matéria-seca (\%) & Proteína bruta (\%) & Energia digestível (Mcal/kg) \\
\hline Capim-elefante & 26,02 & 3,53 & 1,64 \\
Silagem de milho & 31,13 & 7,15 & 3,10 \\
\hline
\end{tabular}

Fonte: Almeida et al. (1999) 
Tabela II. Descrição das categorias que compõem as entradas e as saídas dos sistemas de alimentação (Description of the category inputs and outputs in the alimentation systems).

\begin{tabular}{|c|c|}
\hline \multicolumn{2}{|l|}{ Entradas } \\
\hline Categoria & Descrição \\
\hline Animais & $\begin{array}{l}\text { Potros de descarte com idade de } 06 \text { a } 12 \text { meses, de } 12 \text { a } 24 \text { meses e de } 24 \text { a } 36 \text { meses; Potros me- } \\
\text { dianos com idade de } 06 \text { a } 12 \text { meses, de } 12 \text { a } 24 \text { meses e de } 24 \text { a } 36 \text { meses; Potros Elite com idade } \\
\text { de } 06 \text { a } 12 \text { meses, de } 12 \text { a } 24 \text { meses e de } 24 \text { a } 36 \text { meses; Matrizes; Doadoras; Receptoras; Machos } \\
\text { adultos; Garanhões; Sêmen; Embrião. }\end{array}$ \\
\hline Valor imobilizado & Terra, benfeitorias, equipamentos, máquinas e ferramentas. \\
\hline \multicolumn{2}{|l|}{ Saídas } \\
\hline Categoria & Descrição \\
\hline Valor investido & $\begin{array}{l}\text { Terra (terra de pastagem, de cultura e aluguel de pastos), benfeitorias (curral, galpão de baias, galpão } \\
\text { de serviço, escritório/selaria, farmácia, sala de ração, sala de capim, banheiro, piquetes, baias, pista, } \\
\text { redondel, casa de funcionário, cozinha e refeitório, entre outros), equipamentos (tronco, bombas de } \\
\text { aspersão, microscópio, computador, picadeira, roçadeira costal, sela, manta, cabeçada, embocadura, } \\
\text { rédeas, carroça, carrinho de mão, vagina artificial), máquinas (trator, carreta, gerador), ferramentas (pá, } \\
\text { enxada, foice, facão, garfo, martelo de cravo, alicate, torquez, groza, rineta, ferradura, jacaré, bigorna, } \\
\text { cravo, tosqueadeira, tesoura, raspadeira, mangueira de limpeza, martelo de cerca, torquez de cerca) } \\
\text { e cercas (arame farpado, porteira, grampo, moirão e régua). }\end{array}$ \\
\hline Animais & Matrizes, Doadoras, Potras, Potros, Garanhões, Embriões, Receptoras e Burro (Serviço). \\
\hline Alimentação animal & $\begin{array}{l}\text { Ração de mantença, ração de potros, ração de garanhão, sal mineral, suplemento mineral vitamínico } \\
\text { e silagem. }\end{array}$ \\
\hline Sanidade animal & $\begin{array}{l}\text { lodo, álcool, unguento, pomadas, carrapaticida, vermífugos, antibióticos, antinflamatórios, soros, vacinas, } \\
\text { agulhas, seringas, algodão, gaze, cateter, exames AIE e Mormo, entre outros. }\end{array}$ \\
\hline Reprodução animal & Veterinário, embrião confirmado, sêmen, hormônios. \\
\hline Pastagem e capineira & Pastagem formada, capineira formada, adubo, herbicida. \\
\hline Cultivo do milho & $\begin{array}{l}\text { Análise de solo, aluguel de trator, calcário dolomítico, semente, adubo de semeadura, adubo de co- } \\
\text { bertura, herbicidas e mão de obra. }\end{array}$ \\
\hline Mão de obra & Fixa (gerente e funcionários) e temporária (funcionários eventuais). \\
\hline
\end{tabular}

(VPL) e a taxa interna de retorno (TIR), conforme metodologia proposta por Blank e Tarquin (2008), como ferramentas que auxiliam os produtores na tomada de decisão. A tomada de decisão nos resultados obtidos para o VPL foi a seguinte: se o VPL for maior ou igual a zero, a atividade é viável; caso contrário, é inviável financeiramente. A TIR foi comparada com base na TMA adotada, onde a atratividade do sistema de alimentação se dá quando a TIR for maior ou igual à TMA escolhida.

Após a análise dos indicadores, foi realizada a análise de sensibilidade, de modo a identificar quais os itens estariam influenciando nos resultados obtidos para o VPL (Melo et al., 1999), diante das oscilações de preços ocorridas no mercado, considerando sempre uma variação em $10 \%$, sempre no sentido desfavorável dos itens componentes de cada sistema de alimentação. Nas condições de mercado, a variação considerada foi de acréscimo nos custos do sistema de alimentação e decréscimo nas receitas advindas com a exploração da atividade. O VPL que sofreu a influência foi aquele obtido quando se considerou uma taxa de desconto de $10 \%$ sobre o fluxo de caixa de cada sistema de alimentação.

A análise de risco foi realizada aplicando-se o método de Monte Carlo, de acordo com a metodologia proposta por Turban (1993), que considerou o efeito do risco de cada sistema de alimentação se tornar in- viável financeiramente, diante das variações de preços ocorridas no mercado para cada componente do fluxo de caixa identificado na análise de sensibilidade. A geração aleatória de diferentes fluxos de caixa, considerando os preços determinados no mercado e limitados pela distribuição triangular (Hertz, 1964) permitiu a geração de 50.000 combinações para cada fluxo de caixa, considerando os itens de maior impacto negativo sobre o VPL dos sistemas, o que levou a determinação da probabilidade de insucesso de cada sistema de alimentação.

Na determinação do tempo de recuperação do capital investido em cada sistema de alimentação foi utilizado o método do payback descontado proposto por Blank \& Tarquin (2008).

\section{RESULTADOS}

A viabilidade econômico-financeira dos sistemas de alimentação foi analisada por meio dos resultados obtidos nos indicadores econômicos de rentabilidade: valor presente líquido e taxa interna de retorno (tabela III), em um horizonte temporal de 12 anos, período este considerado de longo prazo que compreendeu a vida útil das cercas utilizadas na atividade pecuária. Os sistemas de alimentação apresentaram resultados positivos para o VPL quando submetidos a uma taxa de desconto de $10 \%$ ao ano, com valores de $\mathrm{R} \$ 300.414,56$ e $\mathrm{R} \$ 390.872,67$, para os sistemas que 
Tabela III. Valor Presente Líquido - VPL, em R\$, submetido a diferentes taxas de desconto e Taxa Interna de Retorno - TIR, em \%, obtida para os sistemas de alimentação equina (Net present value - NPV, in R\$, under different discount rates and internal rate of return - IRR, in \%, obtained for each equine alimentation systems).

\begin{tabular}{|c|c|c|c|c|c|}
\hline \multirow{2}{*}{ Sistema de alimentação } & \multicolumn{4}{|c|}{ VPL } & \multirow{2}{*}{ TIR } \\
\hline & $8 \%$ & $10 \%$ & $12 \%$ & $15 \%$ & \\
\hline Capim Elefante & $930.559,79$ & $300.414,56$ & $-216.353,43$ & $-828.281,57$ & 11,11 \\
\hline Silagem de Milho & $1.025 .604,73$ & $390.872,67$ & $-129.856,05$ & $-746.774,21$ & 11,46 \\
\hline
\end{tabular}

1.00 US $\$=3,10 \mathrm{R} \$(17 / 03 / 2017)$

utilizaram capim-elenfante e silagem de milho como fonte de suplementação alimentar, respectivamente. O sistema de alimentação que utilizou como fonte de suplementação alimentar, a silagem de milho foi aquele que apresentou a maior rentabilidade financeira, na ordem de $11,46 \%$ ao ano, quando comparado ao sistema de alimentação que utilizou o capim-elefante $(11,11 \%$ ao ano).

A fim de identificar os itens mais relevantes que exerceram impacto negativo sobre os resultados do VPL nos sistemas de alimentação, procedeu-se a análise de sensibilidade. Analisando os itens de produção classificados como saídas, em que houve dispêndio de capital financeiro destinado a aquisição de insumos ou contratação de serviços que compuseram os fluxos de caixa nos sistemas de alimentação foi observado que o capital financeiro imobilizado na aquisição do rebanho foi aquele que apresentou maior impacto sobre os resultados do VPL, seguido pelo valor imobilizado na aquisição de áreas e no pagamento de mão de obra (tabela IV). Analisando os itens componentes de cada categoria classificada no fluxo de caixa, observou-se que os preços de comercialização (compra e venda) das éguas doadoras foram aqueles que exerceram maior impacto negativo sobre os resultados do VPL nos dois

Tabela IV. Mudança do VPL, em R\$, decorrente de uma variação de $10 \%$ dos preços dos itens que compõem as saídas dos sistemas de alimentação, por categoria, para uma taxa de desconto de $10 \%$ ao ano (Change de $\mathrm{NPV}$, in $\mathrm{R} \$$, to a variation in the unfavorable direction, $10 \%$ in prices components of outputs alimentation systems, per category, to $10 \%$ per year of discount rate).

\begin{tabular}{|c|c|c|}
\hline Sistema de alimentação & Categoria & $\mathrm{R} \$$ \\
\hline \multirow{13}{*}{ Capim-elefante } & Compra de animais & $-251.477,01$ \\
\hline & Aquisição de áreas & $-93.067,02$ \\
\hline & Pagamento de mão de obra & $-81.852,64$ \\
\hline & Despesas com alimentação & $-47.530,26$ \\
\hline & Despesas com reprodução & $-41.200,93$ \\
\hline & Construção de benfeitorias & $-19.182,24$ \\
\hline & Despesas com sanidade & $-6.969,57$ \\
\hline & Despesas com formação de capineira & $-6.792,00$ \\
\hline & Despesas com instalação das cercas & $-4.374,54$ \\
\hline & Compra de máquinas & $-3.678,51$ \\
\hline & Compra de equipamentos & $-3.140,91$ \\
\hline & Compra de ferramentas & $-1.256,34$ \\
\hline & Manutenção da pastagem & $-69,80$ \\
\hline \multirow{13}{*}{ Silagem de milho } & Compra de animais & $-251.476,98$ \\
\hline & Aquisição de áreas & $-93.067,02$ \\
\hline & Pagamento de mão de obra & $-63.845,07$ \\
\hline & Despesas com reprodução & $-41.200,91$ \\
\hline & Despesas com plantio de milho para silagem & $-34.209,67$ \\
\hline & Despesas com alimentação & $-29.074,22$ \\
\hline & Construção de benfeitorias & $-19.182,15$ \\
\hline & Despesas com sanidade & $-6.969,29$ \\
\hline & Despesas com instalação das cercas & $-4.374,50$ \\
\hline & Compra de máquinas & $-3.678,48$ \\
\hline & Compra de equipamentos & $-3.140,79$ \\
\hline & Compra de ferramentas & $-1.256,21$ \\
\hline & Manutenção da pastagem & $-69,79$ \\
\hline
\end{tabular}


sistemas de alimentação, seguido pelo preço de compra de potras (tabela V).

Comparando os sistemas de alimentação (tabela IV), pode-se observar que a mão de obra $(19,45 \%)$ e a alimentação $(11,30 \%)$ foram itens que se destacaram como extremamente importantes no sistema de alimentação que utilizou o capim-elefante como fonte de suplementação alimentar, ao passo que no sistema que utilizou a silagem de milho os itens de grande relevância foram à mão de obra $(15,44 \%)$ e os custos com a reprodução $(10,18 \%)$.

A alimentação animal com uso de ração balanceada é um item que exerce grande influência nos resultados dos sistemas de produção animal. No sistema de suplementação alimentar que utilizou capim-elefante, observou-se o aumento no custo com ração balanceada para os equinos, devido à necessidade de atender as exigências nutricionais diárias dos animais e suprir as deficiências provenientes do capim-elefante.

Os sistemas de alimentação apresentaram baixo risco financeiro para investimento quando considerada uma taxa de desconto de $10 \%$ ao ano (tabela VI), taxa esta superior a taxa mínima de atratividade considerada no mesmo período que foi na ordem de $7,88 \%$ ao ano.

A determinação do risco foi realizada a partir da geração de 50.000 VPLs, considerando o preço mínimo, o preço mais provável e o preço máximo, ocorrido durante o período de estudo das principais variáveis aleatórias identificadas na análise de sensibilidade. A distribuição das frequências acumuladas foram apresentadas nas figuras 1 e 2 . Na análise probabilística do risco se considerou apenas a flutuação dos preços de mercado, limitados pela distribuição triangular, conforme metodologia proposta por Hertz (1964).

O tempo de recuperação do capital investido ( $p a-$ yback descontado) nos sistemas de alimentação foi de 11 anos e 1 mês para o sistema de alimentação que utilizou capim-elefante e de 10 anos e 7 meses para o sistema de alimentação que utilizou a silagem de milho, como fonte de suplementação alimentar para o rebanho.

\section{DISCUSSÃO}

Por apresentarem resultados positivos para o VPL a uma taxa de desconto de $10 \%$ ao ano, os sistemas de alimentação foram viáveis financeiramente. O sistema que utilizou como fonte de suplementação alimentar, a silagem de milho foi aquele que apresentou a maior rentabilidade financeira, quando comparado ao sistema de alimentação que utilizou o capim-elefante. Os sistemas de alimentação avaliados foram atrativos para investimento, uma vez que apresentaram resultados para a TIR superiores a taxa mínima de atratividade (TMA), considerada neste trabalho, que teve como referencia, os rendimentos médios obtidos com a caderneta de poupança para o ano de 2015, que foi na ordem de 7,88\% ao ano (Portal Brasil, 2016). Descontando-se a inflação registrada no mesmo período $(6,40 \%)$, podese concluir que a taxa real obtida nos sistemas de alimentação foram de 5,03\% e 4,71\%, para os sistemas de alimentação que adotaram silagem de milho e capimelefante, respectivamente.

Estudos sobre a viabilidade técnica e econômica no uso de diferentes formas de suplementação alimentar e de sistemas de produção para animais vêm sendo realizados em vários setores do Agronegócio, o que auxiliam na tomada de decisão dos pecuaristas, permitindo o melhor planejamento da atividade e a gestão dos recursos financeiros disponíveis.

A utilização de silagem de milho como fonte de alimentação suplementar para equinos foi recomendada por diversos autores (Domingues, 2009; Raineri \& Stivari, 2013) em substituição ao fornecimento de feno, promovendo a redução dos custos de produção e melhorando a rentabilidade da atividade. No entanto, é preciso avaliar se a substituição irá atender as exigências nutricionais diárias dos animais, baseada no valor nutritivo da fonte de alimento.

Trabalhos que avaliaram o desempenho econômico de diferentes sistemas de produção vêm sendo aplicados ao Agronegócio, objetivando a geração de indicadores econômicos que permitam aos pecuaristas a tomada de decisão de investir. Peres et al. (2005) avaliaram o uso de suplementação alimentar para a

Tabela V. Mudança doVPL, em R\$, decorrente de uma variação de $10 \%$ dos preços dos itens que compõem o fluxo de caixa dos sistemas de alimentação, para uma taxa de desconto de $10 \%$ ao ano (Change de NPV, in R\$, to a variation in the unfavorable direction, $10 \%$ in prices components of cash flow in alimentation systems, to $10 \%$ per year of discount rate).

\begin{tabular}{|c|c|c|}
\hline Sistema de alimentação & Categoria & $\mathrm{R} \$$ \\
\hline \multirow{10}{*}{$\begin{array}{l}\text { Capim elefante } \\
\text { Silagem de milho }\end{array}$} & Preço de venda de Doadoras & $-84.590,21$ \\
\hline & Preço de compra de Doadoras & $-80.848,17$ \\
\hline & Preço de compra de Potras & - 80.457,67 \\
\hline & Preço de compra da terra para pastagem & - $77.555,85$ \\
\hline & Preço de venda de Matrizes & $-64.445,65$ \\
\hline & Preço de venda de Potros (elite 12/24) & $-51.218,58$ \\
\hline & Preço de venda de Potros (medianos 12/24) & $-45.514,74$ \\
\hline & Preço de venda de Garanhões & $-45.381,54$ \\
\hline & Preço de venda de Potros (elite 24/36) & $-44.621,15$ \\
\hline & Preço de compra de Matrizes & $-39.192,08$ \\
\hline
\end{tabular}


Tabela VI. Resultado da análise probabilística do risco: probabilidade, em \%, dos sistemas de alimentação apresentarem Valor Presente Líquido (VPL) negativo, quando submetido a diferentes taxas anuais de desconto de $8 \%, 10 \%, 12 \%$ e $15 \%$ (Result of risk probabilistic analysis: probability, in $\%$, of the alimentation systems presents the Net Present Value (NPV) negative, when subjective to different discount rates annual in the $8 \%$, $10 \%$, $12 \%$ and $15 \%)$.

\begin{tabular}{lccc}
\hline \multirow{2}{*}{ Sistema de alimentação } & \multicolumn{3}{c}{ Taxa de desconto } \\
\cline { 2 - 4 } & $8 \%$ & $10 \%$ & $12 \%$ \\
\hline Capim-elefante & $0,00 \%$ & $2,55 \%$ & $89,17 \%$ \\
Silagem de milho & $0,00 \%$ & $0,67 \%$ & $75,29 \%$ \\
\hline
\end{tabular}

recria de novilhas leiteiras mantidas em pastagens de capim-elefante. No estudo realizado, os resultados obtidos para os indicadores econômicos demonstraram que o uso da suplementação alimentar foi viável economicamente, com rentabilidade financeira variando entre $10,5 \%$ a.a. e $30,1 \%$ a.a. para os diferentes sistemas de produção testados. Peres et al. (2009) avaliaram o fornecimento de diferentes fontes de volumosos como suplementação alimentar para vacas leiteiras mantidas em pastagem de capim-mombaça. Os autores observaram a viabilidade econômica no fornecimento das fontes suplementares de volumosos durante o período outono-inverno, período este em que a pastagem apresentava baixa produção de matéria-seca disponível a alimentação das vacas. Neste estudo, a rentabilidade financeira variou nos sistemas avaliados entre 8,46\% e $11,91 \%$ a.a., sendo esta rentabilidade superior ao custo de oportunidade do capital considerado que foi na ordem de $6,00 \%$ a.a. Sistemas integrados de produção bovina foram avaliados por Oliveira Júnior et al. (2016) sendo observados a viabilidade econômica na adoção da integração lavoura-pecuária-floresta (ILPF) no cerrado brasileiro, tornando-se excelente opção de investimento para a pecuária brasileira. A rentabilidade obtida nos diferentes sistemas ILPF variou entre $10,73 \%$ a.a. e $11,37 \%$ a.a.

Nos sistemas de alimentação (capim-elefante e silagem de milho), observou-se uma igualdade nos itens de maior influência nos resultados do VPL, onde constatou-se que na criação de cavalos, os valores de comercialização dos animais têm grande impacto sobre os resultados financeiros, requerendo do pecuarista um maior controle na compra e venda de animais,

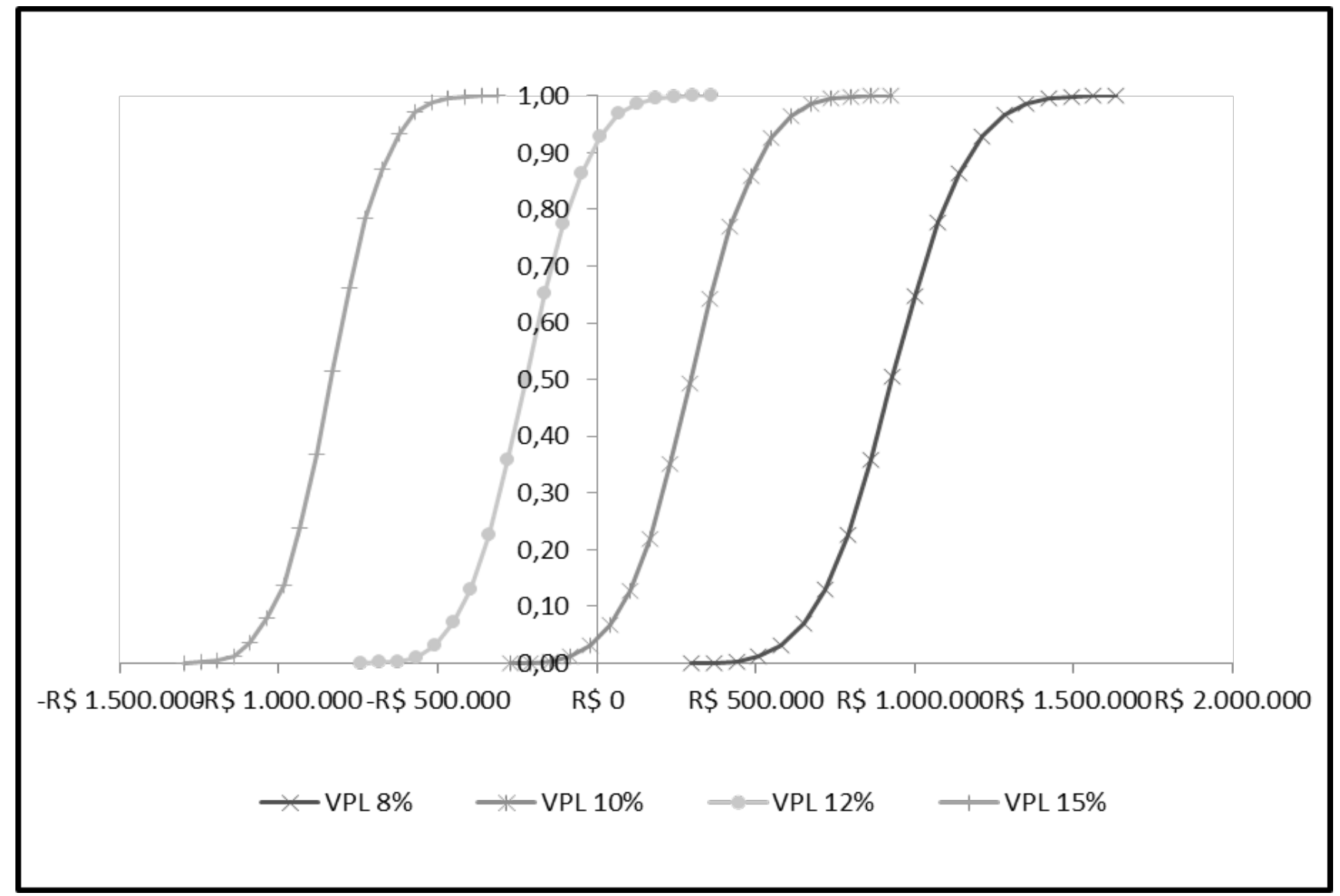

Figura I. Frequência acumulada dos valores presentes líquidos simulados as diferentes taxas de desconto para o sistema de alimentação que utiliza capim-elefante (Cumulative frequency of the net present values simulated the different discount rates for the Elephant-grass alimentation system). 


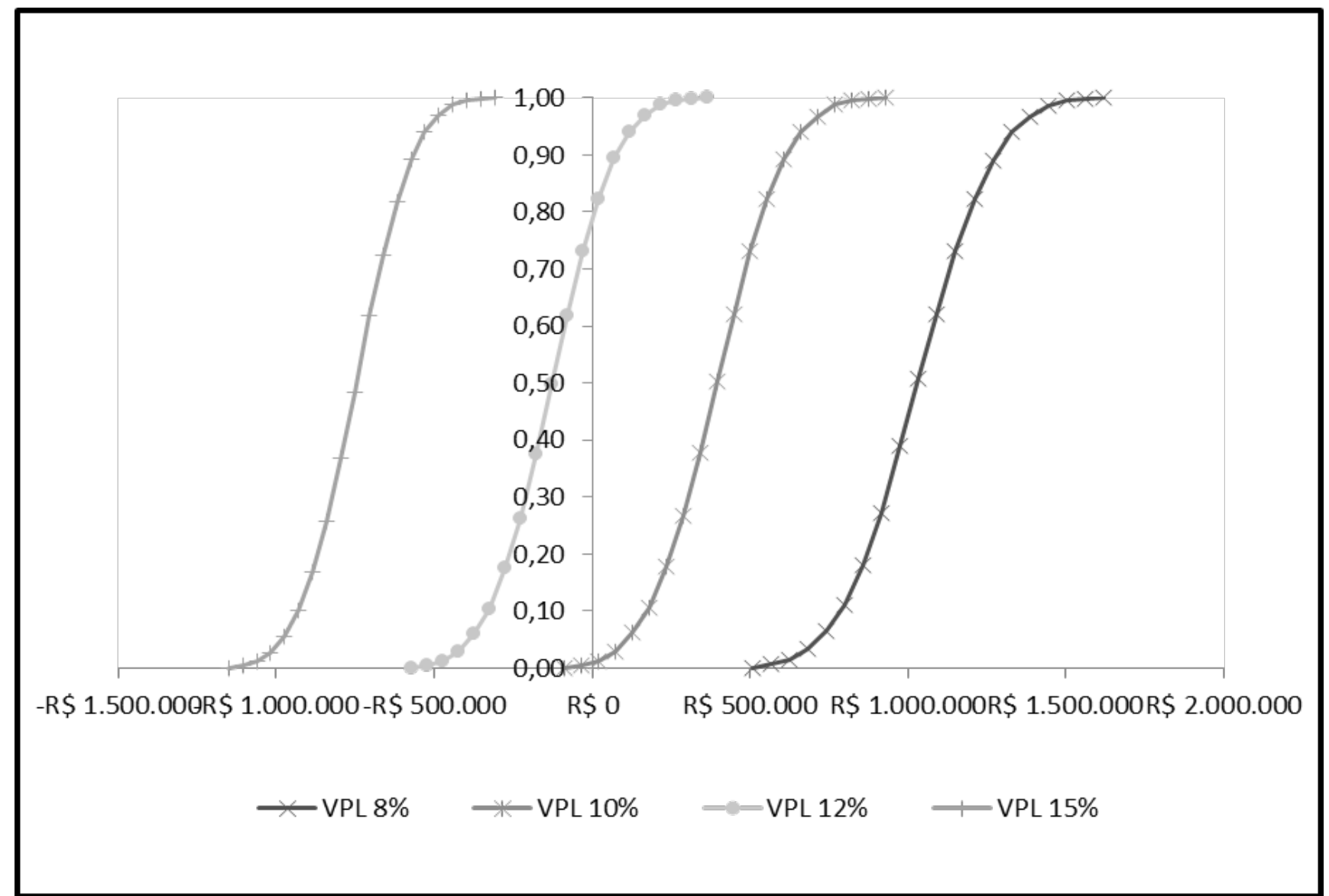

Figura II. Frequência acumulada dos valores presentes líquidos simulados as diferentes taxas de desconto para o sistema de alimentação que utiliza silagem de milho (Cumulative frequency of the net present values simulated the different discount rates for the corn silage alimentation system).

acompanhando diariamente as condições de mercado e planejando o melhor momento para comercializá-los. Essa observação remete ao fato, que nesta atividade, ser bom comprador e bom vendedor é premissa essencial para o sucesso, portanto um planejamento eficaz de compra e venda torna-se de vital importância para viabilizar o negócio.

Quando o produtor realiza a compra de doadoras através de uma empresa leiloeira, é possível deixar acordado a venda de embriões da doadora em leilão realizado pela empresa e com isso amortizar uma parte do dinheiro investido. Santos e Lopes (2014), estudaram os indicadores econômicos de sistemas de produção de leite em confinamento total, relataram que o valor investido em animais foi o item com maior representatividade do "patrimônio sem considerar a terra", em média $60,61 \%$, seguido pelas benfeitorias $(29,42 \%)$, máquinas $(7,69 \%)$ e equipamentos/implementos $(2,28 \%)$. O investimento em matrizes representou $46,16 \%$ de todo o valor investido. Segundo os autores, os valores investidos em animais evidenciaram a importância que se deve dar aos mesmos, como, por exemplo, no momento da aquisição, no manejo diário, no ambiente adequado, entre outros, proporcionando condições para que se possa garantir a máxima produção animal e, consequentemente, maior e mais rápido retorno do capital financeiro investido. Os valores investidos em animais são considerados como sendo custos fixos; portanto, devem-se atingir altas produções por animal para que possam ser "diluídos", refletindo em baixos percentuais do custo total de produção.

No sistema de alimentação que forneceu o capimelefante, os resultados observados se justificaram por necessitar da contratação de dois funcionários temporários a mais que no sistema de alimentação que forneceu silagem de milho, pois as atividades envolvidas com o manejo da capineira envolveram atividades de corte, transporte, processamento e fornecimento, no cocho, da suplementação aos animais. Enderle et al. (2013) avaliaram o custo operacional efetivo de uma Equinocultura e constataram que a variável mão de obra contribuiu, em média, com $36 \%$ na formação do custo operacional efetivo total. Este valor foi relacionado às exigências da atividade por profissionais qualificados e pela manutenção de uma relação entre o número de animais por colaborador.

A alimentação com uso de ração balanceada é um item que exerce grande influência nos resultados dos sistemas de produção animal. No sistema de suplementação alimentar que utilizou capim-elefante, observou-se o aumento no custo com ração balanceada para os equinos, devido à necessidade de atender as exigências nutricionais diárias dos animais e suprir as deficiências provenientes do capim-elefante. 
$\mathrm{Na}$ análise do risco, conforme citado por Peres et al. (2008) não foram consideradas as influências provocadas por fenômenos naturais ou interferências climáticas que promovessem alteração nos indicadores zootécnicos. Diante disso, o risco econômico-financeiro dos sistemas de alimentação, quando considerada a taxa de desconto de $10 \%$ ao ano, pode ser considerado baixo para investimento, oferecendo aos pecuaristas sistemas de alimentação que quando explorados corretamente proporcionarão bons rendimentos zootécnicos ao rebanho e econômicos aos pecuaristas.

Em ambos os sistemas de alimentação, o retorno do investimento ocorreu no longo prazo, período este considerado por alguns autores (Varian, 2000; Marion, 2014) como sendo aquele em que o investimento se torna variável, permitindo ao investidor ter a possibilidade de planejar e modificar o tamanho, forma e a escala de produção de seu empreendimento.

Aliado aos resultados econômicos apresentados, ressalta-se a importância de uma análise de mercado quando se optar pela adoção de qualquer sistema de alimentação, pois se faz necessário conhecer as condições disponíveis na região para o sucesso do investimento. A disponibilidade da mão de obra é essencial para garantir o funcionamento do sistema de alimentação que utilizou capim-elefante, ao passo que a contratação de serviços terceirizados para a produção de silagem de milho, tornou-se imprescindível para o sucesso no uso daquele sistema de alimentação que tem como base o fornecimento da silagem de milho no arraçoamento dos animais. É de extrema importancia que antes de concluída a tomada de decisão sobre qual sistema adotar, o pecuarista analise se as peculiaridades de cada sistema de alimentação estarão sendo atendidas e disponíveis na região.

\section{CONCLUSÕES}

Os sistemas de alimentação para equinos são viáveis financeiramente, a uma taxa de desconto de $10 \%$ a.a.

O uso de capim-elefante ou silagem de milho na alimentação de equinos como forma de suplementação alimentar apresentam rentabilidade financeira atrativa para sua adoção, quando comparada a taxa mínima de atratividade considerada que foi na ordem de 7,88\% a.a.

O sistema de alimentação que utiliza a silagem de milho como fonte de suplementação alimentar apresenta maior rentabilidade ( $11,46 \%$ a.a.) e proporciona uma alimentação de melhor qualidade para os animais, quando comparado ao sistema de alimentação que adota o capim-elefante (11,11\% a.a.).

O preço de compra e venda de animais utilizados como doadoras na criação de cavalos são aqueles de maior relevância nos sistemas de alimentação, o que influencia diretamente na tomada de decisão do pecuarista e nos resultados dos indicadores econômicos.

O risco econômico-financeiro para investimento nos sistemas de alimentação é baixo, entre 0,67\% e 2,55\%, quando submetidos a uma taxa de desconto de $10 \%$ a.a.

Para os sistemas de alimentação que utilizam suplementação volumosa, o tempo necessário para recuperação do capital financeiro investido ocorre no longo prazo, acima de 10 anos de exploração da atividade.

\section{BIBLIOGRAFIA}

Almeida, MIV, Ferreira, WM, Almeida, FQ, Saint-Just, CA, Gonçalves, LC \& Rezende, ASC 1999, 'Valor nutritivo do capim-elefante (Penninsetum purpureum, Schum) do feno de alfafa (Medicago sativa, L.) e do feno de capim coast-cross (Cynodon dactilon, (L.) Pers.) para equinos', Brazilian Journal of Animal Science, vol. 28, no. 4, pp. 743-52.

Associação Brasileira dos Criadores do Cavalo Mangalarga Marchador - ABCCMM 2017, Nossos associados, Belo Horizonte, acessado 10 maio 2017, <http://www.abccmm.org.br/nossos-associados>.

Blank, L \& Tarquin, A 2008, Engenharia econômica, $3^{a}$ Ed, McGrawHill, São Paulo, Brasil.

Brandi, RA \& Furtado, CE 2009, 'Importância nutricional e metabólica da fibra na dieta de equinos', trabalho apresentado na $46^{\circ}$ Reunião Anual da Sociedade Brasileira de Zootecnia, Maringá, 14-17 Julho.

Brasil, Ministério da Agricultura, Pecuária e Abastecimento - MAPA 2016, Revisão do estudo do complexo do agronegócio do cavalo, Brasília, acessado 10 março 2017, <http://www.agricultura.gov.br/assuntos/camaras-setoriais-tematicas/documentos/camaras-setoriais/ equideocultura/revisao-do-estudo-do-complexo-do-agronegociodo-cavalo/>.

Buza, MH, Holden, LA, White, RA \& Ishler, VA 2014 'Evaluating the effect of ration composition on income over feed cost and milk yield', Journal of Dairy Science, vol. 97, no. 5, pp. 3073-80.

CEPEA - Centro de Estudos Avançados em Economia Aplicada/EsalqUSP. Dimensionamento do PIB do Agronegócio do estado do Rio de Janeiro. Piracicaba, 2012. (Relatório Parcial).

CEPEA - Centro de Estudos Avançados em Economia Aplicada/Esalq-USP. Piracicaba, acessado 27 maio 2019, <https://www.cepea.esalq.usp. $\mathrm{br} / \mathrm{br} / \mathrm{pib}$-do-agronegocio-brasileiro.asp $>$.

Dittrich, JR, Melo, HA, Afonso, AMCF \& Dittrich, RL 2010, 'Comportamento ingestivo de equinos e a relação com o aproveitamento das forragens e bem-estar dos animais', Brazilian Journal of Animal Science, vol. 39 , no. supl. especial, pp. 130-37.

Domingues, JL 2009, 'Uso de volumosos conservados na alimentação de equinos', Brazilian Journal of Animal Science, vol. 38, no. supl. especial, pp. 259-69.

Enderle, RX, Curcio, BR, Boff, ALN, Santos, FCC \& Burck, GR 2013, 'Planejamento e gestão de custos: estudo de caso de uma empresa do segmento agropecuário', Revista de Ciências Gerenciais, vol. 17 , no. 26, pp. 145-56.

Fundação Getúlio Vargas - FGV 2016, Índice Geral de Preços - Disponibilidade Interna: Revisão atualizada diariamente, Rio de Janeiro, acessado 13 maio 2016, <http://www.antigofgrdados.fgr.br>.

Garcia, TR 2012, 'Digestibilidade dos nutrientes da dieta e desempenho físico de éguas mangalarga marchador suplementadas com Saccharomyces cerevisiae durante treinamento em esteira ergométrica', Tese de Doutorado, Universidade Federal de Minas Gerais, Belo Horizonte, Brasil.

Hertz, OB 1964, 'Risk analysis in capital investment', Harvard Business Review, vol. 42, no. 1, pp. 95-106.

Hoskin, SO \& Gee, EK 2004, 'Feeding value of pastures for horses', New Zealand Veterinary Journal, vol. 52, no. 6, pp. 332-41.

Lewis, LD 2000, Nutrição clínica equina: alimentação e cuidados, Rocca, São Paulo, Brasil.

Lopes, MA, Cardoso, MG, Carvalho, FM, Lima, ALR, Dias, AS \& Carmo, EA 2007, 'Efeito do tipo de sistema de criação nos resultados econômicos 
de sistemas de produção de leite na região de Lavras (MG) nos anos 2004 e 2005', Ciência Animal Brasileira, vol. 8, no. 3, pp. 359-71. Marion, JC 2014, Contabilidade rural, Atlas, São Paulo, Brasil.

Melo, ACG, Gorenstin, BG, Oliveira, AM, Maceira, MEP, Reis, MS \& Faria, SNG 1999, 'Análise financeira de projetos de investimento sob o enfoque de incertezas', trabalho apresentado no $15^{\circ}$ Seminário Nacional de Produção e Transmissão de Energia Elétrica, Foz de Iguaçu, 17-22 Outubro.

Melo, HA 2008, 'Consumo, preferência alimentar, monitoramento clínico, hematológico e bioquímico de equinos alimentados com silagem', Dissertação de Mestrado, Universidade Federal do Paraná, Curitiba, Brasil.

Müller, CE \& Udén, P 2007, 'Preference of horses for grass conserved as hay, haylage or silage', Animal Feed Science and Technology, vol. 132, pp. 66-78.

National Research Council 1989, Nutrient requirements of horses, 5 ed., NRC, Washington, D.C.

National Research Council 2007, Nutrient requirements of horses, 6 ed., NRC, Washington, D.C.

Oaigen, RP, Barcellos, JOJ, Christofari, LF, Neto, JB, Oliveira, TE \& Prates, ER 2009, 'Análise da sensibilidade da metodologia dos centros de custos mediante a introdução de tecnologias em um sistema de produção de cria', Brazilian Journal of Animal Science, vol. 38, no. 6, pp. 1155-62.

Oliveira Júnior, OL, Carnevalli, RA, Peres, AAC, Reis, JC, Moraes, MCMM \& Pedreira, BC 2016, 'Análise econômico-financeira de sistemas integrados para a produção de novilhas leiteiras', Archivos de Zootecnia, vol. 65, no. 250, pp. 203-12.

Peres, AAC, Souza, PM, Vasquez, HM, Silva, JFC, Carvalho, CAB, Carvalho, JBP \& Morenz, MJF 2008, 'Análise financeira sob condições de risco de sistemas de produção de leite na região do Vale do Paraíba, SP', Boletim da Indústria Animal, vol. 65, no. 1, pp. 35-42.
Peres, AAC, Vasquez, HM, Silva, JFC, Souza, PM, Soares, CS, Barros, SCW, Morenz, MJF \& Detmann, E 2005, 'Avaliação produtiva e econômica de sistemas de produção bovina em pastagens de capimelefante', Brazilian Journal of Veterinary and Animal Sciences, vol. 57, no. 3, pp. 367-73.

Peres, AAC, Vásquez, HM, Souza, PM, Silva, JFC, Villela, OV \& Santos, FC 2009, 'Análise financeira e de sensibilidade de sistemas de produção de leite em pastagens', Brazilian Journal of Animal Science, vol. 38, no. 10, pp. 2072-78.

Portal Brasil 2016, Caderneta de poupança: índices diários, Brasília, acessado 13 maio 2016, <http://www.portalbrasil.net/poupanca. htm>.

Quadros, JBS, Furtado, CE, Barbosa, ED, Andrade, AB \& Trevisan, AG 2004, 'Digestibilidade aparente e desenvolvimento de equinos em crescimento submetidos a dietas compostas por diferentes níveis de substituição do feno de Tifton 85 pela casca de soja' , Brazilian Journal of Animal Science, vol. 33, no. 3, pp. 564-74.

Raineri, C \& Stivari, TSS 2013, 'Utilização da silagem para alimentação de equinos', Pubvet, vol. 7, no. 34, acessado 13 janeiro 2017, <http:// www.pubvet.com.br/artigo/818/utilizaccedilatildeo-da-silagempara-alimentaccedilatildeo-de-equinos>.

Salter, RE \& Hudson, RJ 1979, 'Feeding ecology of feral horses in western alberta', Journal of Range Management, vol. 32, no. 3, pp. 221-25.

Santos, G \& Lopes, MA 2014, 'Indicadores econômicos de sistemas de produção de leite em confinamento total com alto volume de produção diária', Ciência Animal Brasileira, vol. 15, no. 3, pp. 239-48.

Turban E 1993, Decision suport and experts systems: management support systems, Macmillan, New York, United States of America.

Varian, HR 2000, Microeconomia: princípios básicos, Campus, Rio de Janeiro, Brasil. 